\title{
INFORMATION FOR AUTHORS
}

The International Journal of Odonatology (IJO) publishes original articles dealing with research on dragonflies.

There is no page charge. The (first) author of each published article will receive $\mathbf{5 0}$ reprints free of charge. Additional reprints can be ordered when proofs are returned.

Research Papers will be evaluated for publication by an Editorial Board of experienced odonatologists, assisted by external reviewers, who will advise the Editor on the eligibility of submitted manuscripts. A separate section devoted to Notes (i.e. short communications) provides a forum for odonatologists to record short contributions that do not amount to Research Papers yet deserve to be reported in a scientific journal. No reprints will be provided of Notes, which will be printed as space permits. When submitted to IJO, a contribution must not be under consideration for publication in another journal.

Contributions shall be in English, using either British or North American conventions for grammar and spelling. Authors not fluent in English should if possible have their manuscripts checked for correct use of language before submission. Contributors unable to do this are invited to make this known to the Editor in a covering letter. English of low quality and clarity is a major cause of rejection or delay in publication.

Detailed instructions for the preparation of manuscripts (Instructions to Authors) are available on the Worldwide Dragonfly Association website at http://powell.colgate.edu/wda/ dragonfly.htm in a revised version of 29 November 2001.

Contributors are asked to study the Instructions to Authors carefully and to follow them precisely when preparing a manuscript for submission. Contributors who fail to follow these instructions are liable to have manuscripts returned to them before review and to be asked to prepare them in the prescribed format. The Editor observes this policy in order to avoid extra cost and unnecessary expenditure of time by the Editorial Board and reviewers. By submitting a manuscript in the approved format, a contributor can avoid delay in acceptance and publication of a paper, and can materially assist the financial viability of the Association.

The Editor reserves the right to adjust style to achieve a certain standard of uniformity.

Authors are advised, if possible, to have a manuscript reviewed informally by a suitable colleague before submission and, if so, to tell the Editor by whom the manuscript was reviewed.

Colour illustrations can be printed only if subsidised, by the author or a sponsor.

The author (or the corresponding author if there is more than one author) will receive proofs for checking. No new material may be inserted in the text at the time of proof checking except with the Editor's agreement. All joint communications must indicate the name and full postal address of the author to whom proofs and reprints should sent. The postal address and, if available, telephone and fax number and an e-mail address of the corresponding author should be included in the letter of submission.

Manuscripts should be submitted on a diskette or, preferably, attached to an e-mail. The preferred text format is Word. Authors should also send a copy in rich text format.

Manuscripts should be sent directly to:

Dr Reinhard Jödicke. Editor, International Journal of Odonatology, Grossenging 14, D-49699 Lindern, Germany.

All communications with the Editor regarding manuscripts shall preferably be conducted by e-mail at r.joedicke@t-online.de. 